\title{
A Case Study Using Cognitive-Behavioral Therapy- Management of ADHD
}

\author{
Thyagarajan $\mathrm{R}^{1 *}$
}

\section{ABSTRACT}

Attention-deficit/hyperactivity disorder (ADHD) remains one of the most prevalent mental health diagnoses identified in school-age children. Affected children show an increased risk for school failure, social difficulties, and the development of psychiatric co-morbidities. Despite the availability of evidence-based behavioral protocols for managing ADHD-related impairments, psychologists often encounter difficulties involving parents in the sustained implementation of these interventions. Cognitive-behavioral treatment aims to teach children with Attention Deficit Hyperactivity Disorder (ADHD) strategies to help them increase their self-control and problemsolving abilities, through modeling, role playing and self-instruction. Cognitive-behavioral treatment has shown mixed effectiveness regarding ADHD behaviors Cognitive-behavioral therapy (CBT) can address treatment obstacles through emphasizing psycho-education, the development of a collaborative treatment context. This article presents a case study of Jay, a 9year-old child with ADHD. He was supplemented with child-focused CBT strategies by the psychologist and parental behavioral management training by the parent. This case study outlines a central role of CBT intervention in collaboration with the Parent in managing ADHD children.

Keywords: Attention-Deficit/Hyperactivity Disorder, Parent Behavioral Management, Cognitive Behavior Therapy

Cognitive-behavioral treatment is a theoretical and evidence-based intervention that addresses dysfunctional thoughts and attributions, maladaptive behaviors and cognitive processes through goal-orientated and systematic procedures in either group or individual therapy sessions. Cognitive-behavioral treatment aims to teach children with Attention Deficit Hyperactivity Disorder (ADHD) strategies to help them increase their self-control and problem-solving abilities, through modeling, role playing and self-instruction. Cognitive-behavioral treatment has shown mixed effectiveness regarding ADHD behaviors. In particular, this review will focus on the parental perspective. A number of issues including methodological quality and generalizability are raised, but overall it is recommended that cognitive-behavioral treatment continue to be considered appropriate for treating children with ADHD.

\footnotetext{
${ }^{1}$ Lecturer, Institute of Mental Health (Department of Psychology), Sweekaar Academy of Rehabilitation Sciences, Secunderabad, Telangana, India

*Responding Author

(C) 2016 I R Thyagarajan; licensee IJIP. This is an Open Access Research distributed under the terms of the Creative Commons Attribution License (http://creativecommons.org/licenses/by/2.0), which permits unrestricted use, distribution, and reproduction in any Medium, provided the original work is properly cited.
} 
The cognitive-behavioral model highlights the central role of thoughts and attributions in understanding an individual's emotional and behavioral life. The core techniques involve helping individuals to identify patterns of thinking that interfere with their optimal functioning (Levine \& Anshel, 2011). No single set of methods defines cognitive-behavioural treatment. However, treatment is governed by two overarching main themes: the conviction that cognitive processes influence emotion, motivation and behaviour and the use of cognitive and behaviour-change techniques in a pragmatic (hypothesis-testing) manner (Butcher, Mineka, \& Hooley, 2010).

\section{Cognitive-behavioural treatment in relation to children with ADHD}

Due to some limited effects of psycho stimulant medications on decreasing the cardinal symptoms of ADHD (Hechtman, Weiss, \& Perlman, 1984; Gittelman \& Kanner, 1986) researchers explored alternative treatment approaches such as cognitive-behavioural treatment. Carried out by a therapist, cognitive-behavioural treatment sessions attempt to teach children strategies to help them increase their self-control and problem-solving abilities, through modelling, role playing and self instruction (Kendall \& Braswell, 1985; Kendall, Padever, \& Zupan, 1980) to: (1) define the nature of the problem; (2) reflect on all the possible solutions; and (3) choose one solution and evaluate its outcome (Kendall \& Braswell, 1985).

Most current models of ADHD emphasize the deficiencies in the executive functioning skills of behavioral inhibition and self-regulation (Barkley, 2006). These deficiencies in turn manifest themselves in overt behaviors, such as sustaining attention to academic tasks and inhibiting excessive motor activity. Cognitive behavioral proponents recognise the goodness of fit between these highlighted deficits in children with ADHD and the self-regulatory focus of cognitivebehavioral treatment (Hinshaw \& Melnick, 1992). Relatedly, the proponents of cognitive behavioral approach contend that the maintenance of treatment gains can be achieved only through teaching a generalised set of cognitive mediational (self-talk) skills that children with ADHD can internalise.

\section{CBT and Bandura's Theory}

The cognitive-behavioral perspective can take a variety of forms and draws on a range of psychological theories. For example, Bandura's theory of self-efficacy - the view that one can achieve desired goals $(1986,1997)$ and that the beliefs individuals hold about their capabilities have a strong influence on the ways in which they behave (Usher \& Pajares, 2008) - is an early example of a cognitive-behavioral perspective. He posited that cognitive-behavioral treatments work in large part by improving self-efficacy.

Beck's cognitive model makes the assumption that problems result from biased processing of external events or internal stimuli. These biases distort the way that person makes sense of the experiences he or she has in the world, leading to cognitive errors. Beck (2005) argues that underlying these biases is a relatively stable set of schemas that contain dysfunctional beliefs. 
When the schemas become activated they bias information processing. The central focus in treatment is therefore to alter distorted and maladaptive cognitions and their underlying schemas; this is achieved through making individuals aware of and exploring the connections between thoughts and emotional responses and later learning and practicing strategies to better deal with difficult external events or internal stimuli. In the case of ADHD for example, the cognitivebehavioral approach helps pupils to understand links between thoughts, feelings and behaviors and that these may result in unhelpful, inappropriate or maladaptive consequences. The therapy also explores learning to change these thoughts, feelings and behaviors to produce more desirable outcomes (NICE, 2009).

ADHD is repeatedly singled out as a challenge for teachers, parents and psychologists, because of the behavioral characteristics commonly demonstrated by children with this disorder (Langberg, Froelich, Loren, Martin, \& Epstein, 2008). Because ADHD is associated with poor peer relations and negative self-image (Horn, Ialongo, Greenberg, Packard, \& Smith-Winberry, 1990), children with ADHD are at greater risk as adolescents and adults of several social and emotional problems, including substance abuse and depression (Gray, Riggs, Min, MikulichGilbertson, Bandyopadhyay, \& Winhusen, 2011; Tamm, Trello-Rishel, Riggs, Nakonezny, Acosta, Bailey, \& Winhusen, 2013), and the frequency of academic and career problems is significantly higher in these children compared with the normal population (Jensen, Mrazek, Knapp, Steinberg, Pfeffer, Schowalter, \& Shapiro, 1997; Springer, Phillips, Phillips, Cannady, \& Kerst-Harris, 1992).

Findings on the effectiveness of cognitive-behavioral interventions on ADHD behaviors have been mixed. Literature demonstrates the limitations of cognitive behavioral interventions in directly targeting central ADHD impairments (Abikoff, 1987; Abikoff, 1991). Indeed, despite some early claims of success (e.g. Cameron \& Robinson, 1980), systematic investigations aimed at comparing the benefits of cognitively based interventions with stimulant medications have demonstrated the superiority of the latter (Abikoff, Ganeles, Reiter, Blum, Foley, \& Klein, 1988).

However, other studies show that cognitive-behavior techniques are effective in moderating impulsivity (Kendall \& Braswell, 1982). A recent review by Munoz-Solomando, Kendall, \& Whittington (2008) also suggests that cognitive-behavioral interventions can have beneficial effects delivered in absence of medication or as adjunct to continued routine medication for children with ADHD. Furthermore, current NICE guidelines retain their support for cognitivebehavioral interventions for children with ADHD; they consider group-based cognitivebehavioral interventions to be both effective with children with ADHD and cost efficient. In light of these discordant views, combined with the fact that many reviews are now dated, a re-consideration of the area is necessary. 
The parent's role in supporting the child is crucial, yet literature highlights that parents of children with ADHD often struggle to manage their child's problems, suffering from stress and exhaustion (Green, Mc Ginnity, Meltzer, Ford, \& Goodman, 2005). Further, recent legislation has highlighted the importance of involving parents in treatment options and the treatment process, making the parent's perspective of particular relevance to current practice. As such, this review will focus on the parent's perspective.

\section{CASE PRESENTATION}

\section{Chief Complaints:}

1. Hyperactive

2. Would grab whatever is in hands without prior permission

3. Does not pay attention to what is told

4. Always disturbing his peer group

5. Blurts out answers before a question is completed

6. Pays no attention in school work

7. Delays coping notes at school

\section{HISTORY OF PRESENTING COMPLAINTS}

Master L is 9 years old with a history of ADHD. He is an overactive child from early infancy, and his parents initially attributed his exuberant behavior to the natural tendencies of his sex. The parents tried their best to keep the behavior under control by verbally controlling his discipline and occasionally spanking him.

When he was 3 years of age, his parents came increasingly aware of his hyperactivity impulsivity. There were regular complaints from school regarding his inattention. At the age of 5 years he was diagnosed as ADHD by a psychologist. Their parents accepted the counseling done to help manage their son's condition, but the parents declined use of medication. Later when the child was changed to a new school, teachers complained about his hyperactivity, inattentiveness and distracting peer group, he would never wait for his turn and always impulsive, he would never wait for the question to be completed, and would blurt out answers, which became an hindrance in his understanding and learn more. The parents were called and again adviced to seek the help of a psychologist.

A psychological evaluation was done again and recommended for medication. This time parents accepted and started giving medication. The parents were placed on the defensive all the time and began to feel threatened, stating that "the focus was no longer on the child's condition but on the parental abilities". As a result to attend to children and coordinate their care, unable to navigate the different agencies that had become involved with their family and believing a more disciplinary and controlled environment might help, the parents kept away Mast L from his sibling, Master L was staying at his grandparents home and his other sibling was staying with his 
parents, they would both exchange visit to their home weekly once. Neither environment had an effect on his behavior. He continued to be inattentive, hyperactive and impulsive.

\section{DIAGNOSTIC STRATEGIES:}

Table 1 lists the DSM IV criteria for the 3 subtype of ADHD. These are 1. Predominantly inattentive (has at least 6/9 inattentive behaviors, 2. Predominantly hyperactive and impulsive (has 6/9 hyperactive and impulsive behaviors), and 3. Combined (has at least 6/9 for both inattention and hyperactive-impulsive behaviors).

\section{Table 1. DSM-IV Diagnostic Criteria for Attention-Deficit/Hyperactivity Disorder}

Six or more symptoms from the specified category (or categories) listed below must have persisted for at least 6 months to a degree that is maladaptive and inconsistent with developmental level.

314.01 Attention-deficit/hyperactivity disorder, combined type: categories A1 and A2 314.00 Attention-deficit/hyperactivity disorder, predominately inattentive type: category A1 314.01 Attention-deficit/hyperactivity disorder, predominately hyperactive-impulsive type: category A2

314.9 Attention-deficit/hyperactivity disorder not otherwise specified: prominent symptoms of inattention or Hyperactivity-impulsivity that do not meet criteria for attention-deficit/hyperactivity disorder

\section{A1: Inattention}

1. Often Fails to give close attention to details or makes careless mistakes in schoolwork, work, or other activities

2. Has difficulty sustaining attention in tasks or play activities

3. Does not seem to listen when spoken to directly

4. Does not follow through on instructions and fails to finish schoolwork, chores, or duties in the workplace (not due to oppositional behavior or failure to understand instructions)

5. Has difficulty organizing tasks and activities

6. Avoids, dislikes, or is reluctant to engage in tasks that require sustained mental effort (such as schoolwork or homework)

7. Loses things necessary for tasks or activities (Eg, toys, school assignments, pencils, books, or tools)

8. Is easily distracted by extraneous stimuli

9. Is forgetful in daily activities

\section{A2: Hyperactivity-Impulsivity}

\section{Hyperactivity}

1. Often Fidgets with hands or feet or squirms in seat

2. Leaves seat in classroom or in other situations in which remaining seated is expected

3. Runs about or climbs excessively in situations in which is inappropriate 
(in adolescents or adults, may be linked to subjective feelings of restlessness)

4. Has difficulty playing or engaging in leisure activities quietly

5. Is "on the go" or often acts as if "driven by a motor"

6. Talks excessively

\section{Impulsivity}

1. Often Blurts out answers before questions have been completed

2. Has difficulty awaiting turn

3. Interrupts or intrudes on others (Eg, butts into conversations or games) Additional required criteria

B. Some hyperactive-impulsive or inattentive symptoms that cause impairment were present before 7 years of age

C. Impairment in 2 or more settings (eg, at school, work, or home)

D. Clinically significant impairment in social, academic, or occupational functioning

E. Symptoms do not occur exclusively during the course of a pervasive developmental disorder, schizophrenia, or other psychotic disorder and are not better accounted for by another mental disorder (Eg: mood disorder, anxiety disorder, dissociative disorder, or a personality disorder)

\section{ADHD Rating Scale}

Child's Name:

Age:

Date:

Completed By: Parent__ Teacher__ Other

For each line below, please put an " $\mathrm{x}$ " in the box that best describes the child's behaviour over the last 6 months

\begin{tabular}{|l|l|l|l|l|}
\hline $\begin{array}{l}\text { BEHAVIOR Always } \\
\text { INATTENTION }\end{array}$ & $\begin{array}{l}\text { Very } \\
\text { often }\end{array}$ & Somewhat & $\begin{array}{l}\text { Rarely or } \\
\text { Never }\end{array}$ \\
$\begin{array}{l}\text { Fails to give close attention to details or } \\
\text { makes careless mistakes in } \\
\text { schoolwork/homework. }\end{array}$ & & & & \\
\hline $\begin{array}{l}\text { Has difficulty keeping attention on tasks or } \\
\text { play activities. }\end{array}$ & & & & \\
\hline $\begin{array}{l}\text { Does not seem to listen when spoken to } \\
\text { directly. }\end{array}$ & & & & \\
\hline $\begin{array}{l}\text { Does not follow through on instructions and } \\
\text { fails to finish schoolwork or chores. }\end{array}$ & & & & \\
\hline Has difficulty organizing tasks and activities. & & & & \\
\hline $\begin{array}{l}\text { Avoids or strongly dislikes tasks that require } \\
\text { sustained mental effort (e.g., homework) }\end{array}$ & & & & \\
\hline $\begin{array}{l}\text { Loses things necessary for tasks or activities } \\
\text { (e.g., pencils, books, toys, etc). }\end{array}$ & & & & \\
\hline
\end{tabular}




\begin{tabular}{|l|l|l|l|l|}
\hline Is easily distracted by outside stimuli. & & & & \\
\hline Is forgetful in daily activities. & & & & \\
\hline Total for Inattention & & & & \\
\hline BEHAVIOR & & & & \\
HYPERACTIVITY \& IMPULSIVITY & & & & \\
\hline Fidgets with hands or feet or squirms in seat. & & & \\
\hline $\begin{array}{l}\text { Leaves seat in situations in which remaining } \\
\text { seated is } \\
\text { expected (e.g., dinner table). }\end{array}$ & & & & \\
\hline $\begin{array}{l}\text { Runs about or climbs in situations where it is } \\
\text { inappropriate }\end{array}$ & & & & \\
\hline Has difficulty playing quietly. & & & & \\
\hline Is "on the go" or acts "driven by a motor." & & & & \\
\hline Talks excessively. & & & & \\
\hline $\begin{array}{l}\text { Blurts out answers to questions before the } \\
\text { questions have been completed. }\end{array}$ & & & & \\
\hline Has difficulty awaiting turn & & & & \\
\hline $\begin{array}{l}\text { Interrupts others or intrudes on others (e.g., } \\
\text { butts into games) }\end{array}$ & & & & \\
\hline Total for Hyperactivity and Impulsivity & & & & \\
\hline
\end{tabular}

Were some of these behaviors present before age 7? Yes _ No _ Unsure _ N/A _

\section{Interpretation of the Scale}

To look for the number of symptoms in the Inattention section in the "Always or very often" and the "Often" columns. To meet the criteria for ADHD inattentive sub-type, there must six or more of these. In other words, the child must have at least six of these symptoms which have persisted for at least 6 months to a degree that is maladaptive (significant impairment in social, academic, or occupational functioning) and inconsistent with developmental level.

Next to look at the totals for the Impulsivity and Hyperactivity section. To be consistent with the criteria for ADHD hyperactive sub-type, six or more of these symptoms should be in the "Always or very often" and the "Often" categories.

If the criteria for both inattention and hyperactivity are met (i.e., six or more in both), this is an ADHD combined sub-type.

\section{Procedure}

CBT was given for 45 minutes thrice a week. Twelve sessions were given, Cognitive-behavioral treatment sessions were carried out to teach strategies to help them increase their self-control and problem-solving abilities, through modeling, role playing and self instruction (Kendall \& 
Braswell, 1985; Kendall, Padever \& Zupan, 1980), medications was also used to decrease the core symptoms of ADHD (Hechtman, Weiss, \& Perlman, 1984; Gittelman \& Kanner, 1986)

Where they have to:

(1) Identify nature of the problem

(2) Start acting on all the possible solutions

(3) Take any one solution and evaluate its outcome

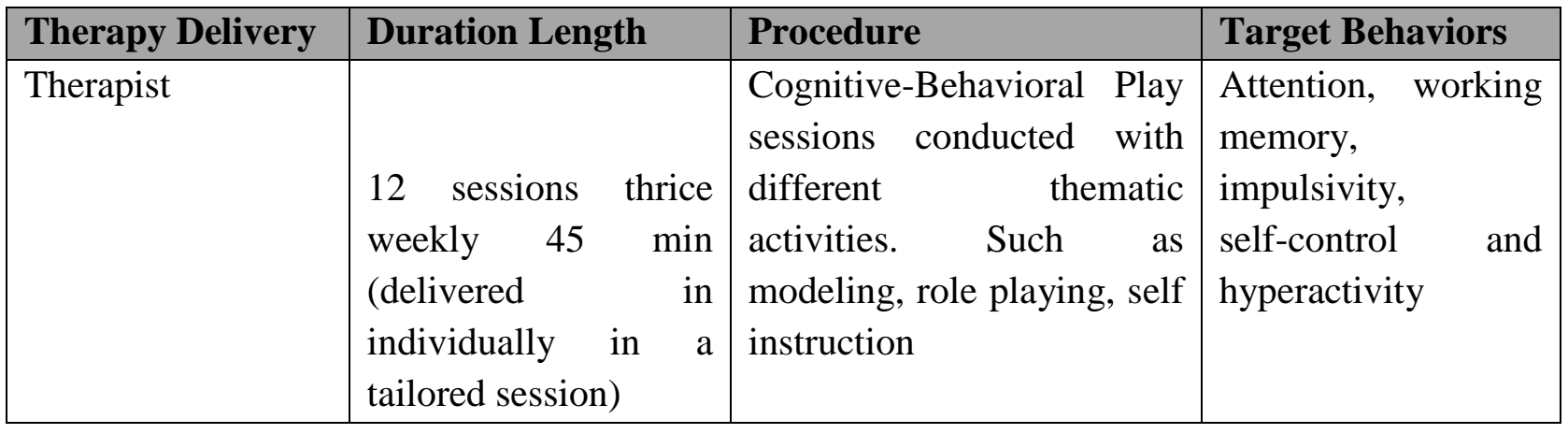

Fehlings et al., 1991; Horn et al., 1990; Miranda \& Jesús Presentación, 2000 in their studies also implemented cognitive-behavioural treatment that instructed children in similar strategies such as problem solving, self-instructional training, self-monitoring and self-control therapy. The studies used similar methods of training, such as modeling, role playing and guided practice.

Froelich et al. (2002) reported discussing individually relevant academic or social problems. Parents were taught about CBT and that achieved significant findings across all measures and the authors felt that emphasis on generalisation of newly acquired skills played a key part in achieving this outcome measures.

Attention Deficit Hyperactivity Rating Scale (ADHD RS), was administered pre-post intervention to find the results in all the three specific domains, Inattention, Hyperactivity and Impulsivity

\section{In addition to CBT, Parental Behavioral Training was done.}

Parental Behavioral training has a long, successful history as a treatment for children with ADHD (Pelham et aI., 1998), oppositional defiant disorder (ODD) and conduct disorder (CD; Brestan \& Eyberg, 1998), as well as many internalizing disorders (e.g., Silvennan et aL, 1999). Behavioral parent training explicitly provides parents with instruction in the implementation of behavior modification techniques that are based on social learning principles. Parents are taught to identify and manipulate the antecedents and consequences of child behavior, target and monitor problematic behaviors, reward prosocial behavior through praise, positive attention, and tangible rewards, and decrease unwanted behavior through planned ignoring, time out, and other non-physical discipline techniques (e.g., removal of privileges). 
The efficacy of parent training in treating ADHD has been evaluated in at least 28 published studies (for a review, see Chronis, Chacko, Fabiano, Wymbs, \& Pelham, 2004). These studies employed manualized parent training interventions, included children between the ages of 3 and 14, were heterogeneous in design (e.g., randomized, controlled clinical trials, single subject case studies), and combined parent training with various treatment components (e.g., school interventions, social skills training).

Overall, these studies suggested that parent training results in improvements for children with ADHD in several important areas, most notably parent ratings of problem behavior and observed negative parent and child behaviors, with an average effect size of .87 (range=- .09-2.25; Fabiano, Pelham, Coles, Gnagy, \& Chronis, in preparation).

In some cases, parent training has also resulted in improvements in other domains, such as parental reports of stress (e.g., Anastopolous, Shelton, DuPaul, \& Guevern10nt, 1993), and social behavior and acceptance (Pelham et a1., 1988).

\section{Parental activities that helped modify the behaviors of a child were such as}

1. Maintaining a daily Schedule

2. Keeping distraction to a minimum

3. Setting small reachable goals

4. Rewarding positive behavior

5. Using charts and checklist to help the child stay on task

6. Finding activities in which the child can be successful (sports/games)

7. Using Calm discipline (time out was avoided, distraction, removing the child from the situation)

Therapeutic goals were established with the patient and family and therapy goals were initiated.

\section{CBT included:}

- Self instructions training for academic activities

- Controlling anger in peer provocation situations

- Learning self evaluation through instructions

\section{ATTENTION ENHANCEMENT TECHNIQUES}

\begin{tabular}{|l|l|l|}
\hline & Activities & \\
\hline & 1. Grain Sorting & Jay's attention span was only \\
& 2. Coloring & 10 minutes pre intervention, \\
3. Painting & post therapy ie by 12 $2^{\text {th }}$ session \\
4. Letter Cancellation attention span was 30 \\
5. Digit Cancellation
\end{tabular}


SELF INSTRUCTION AND COVERT MODELING

\begin{tabular}{|c|c|c|c|c|}
\hline $\begin{array}{l}\text { Academic } \\
\text { Activities }\end{array}$ & Techniques & Therapist & Jay & Outcome \\
\hline $\begin{array}{l}\text { Delay in copying } \\
\text { notes from the } \\
\text { Black Board }\end{array}$ & $\begin{array}{l}\text { Modeling and } \\
\text { Self Instruction }\end{array}$ & $\begin{array}{l}\text { The Therapist } \\
\text { modeled Jay how } \\
\text { to talk to self i.e } \\
\text { give instructions to } \\
\text { self without } \\
\text { uttering but only in } \\
\text { thought " I will } \\
\text { complete copying } \\
\text { my work from the } \\
\text { black board today" }\end{array}$ & $\begin{array}{l}\text { Jay would talk to } \\
\text { self in thought } \\
\text { that he should } \\
\text { complete copying } \\
\text { the notes from } \\
\text { black board and } \\
\text { would try to do it } \\
\text { as much as } \\
\text { possible }\end{array}$ & $\begin{array}{l}\text { Jay could do } \\
\text { this task to an } \\
\text { extent of } 75 \% \\
\text { by the end of } \\
12^{\text {th }} \text { session of } \\
\text { therapy }\end{array}$ \\
\hline \multirow[t]{2}{*}{$\begin{array}{lr}\text { Controlling } & \text { anger } \\
\text { in } & \text { peer } \\
\text { provocation } & \\
\text { situations } & \end{array}$} & Self Instruction & $\begin{array}{l}\text { Jay was told by the } \\
\text { therapist how to } \\
\text { control anger with } \\
\text { peers at } \\
\text { provocating } \\
\text { situations }\end{array}$ & $\begin{array}{l}\text { Jay would count } \\
\text { numbers from } 1 \\
\text { to } 10 \text { till he } \\
\text { becomes calm } \\
\text { and then leave } \\
\text { the situation, } \\
\text { where he will be } \\
\text { provoked }\end{array}$ & $\begin{array}{l}\text { Jay could } \\
\text { practice this } \\
\text { technique, } \\
\text { and was able } \\
\text { to control his } \\
\text { anger about } \\
80 \%\end{array}$ \\
\hline & $\begin{array}{l}\text { Covert } \\
\text { modeling }\end{array}$ & $\begin{array}{l}\text { Jay was asked to } \\
\text { use his } \\
\text { imagination, } \\
\text { visualizing not } \\
\text { completing the } \\
\text { work (copying } \\
\text { notes from the } \\
\text { board) on time as } \\
\text { the therapist } \\
\text { describes the } \\
\text { imaginary situation } \\
\text { in detail. }\end{array}$ & & \\
\hline
\end{tabular}

\section{Role Playing}

\begin{tabular}{|l|l|l|}
\hline Behavior & Technique & Therapist \\
\hline $\begin{array}{l}\text { Blurt out answers to question } \\
\text { before having been finished } \\
\text { asking question }\end{array}$ & Role Playing & $\begin{array}{l}\text { Therapist "blurting out answers with } \\
\text { impulsivity" while doing a } \\
\text { role play with other people } \\
\text { and also the consequences } \\
\text { were projected }\end{array}$ \\
\hline On the Go always & Role Playing & $\begin{array}{l}\text { Role playing with other } \\
\text { children showing hyperactive } \\
\text { movements }\end{array}$ \\
\hline
\end{tabular}




\section{PHARMACOLOGICAL INTERVENTION:}

Jay was on drug Methyphinedate - Inspiral $10 \mathrm{mg}$ which was given twice a day, 1in the morning and the other in the night

\section{RESULTS}

The effectiveness of cognitive-behavioral treatment on ADHD symptoms in children with ADHD, as measured, was determined by the interactive effect (pre vs. post intervention). Significant interactions were found in all the three specific behavioral areas, but this is likely due to the active 'alternative' treatment (parental behavioral training).

\section{Table 1: Scores Mast L Pre Intervention}

\begin{tabular}{|l|l|}
\hline Pre intervention or Baseline Scores & 9 \\
\hline Inattention & 9 \\
\hline Impulsivity/Hyperactivity & 18 \\
\hline Total Score & \\
\hline
\end{tabular}

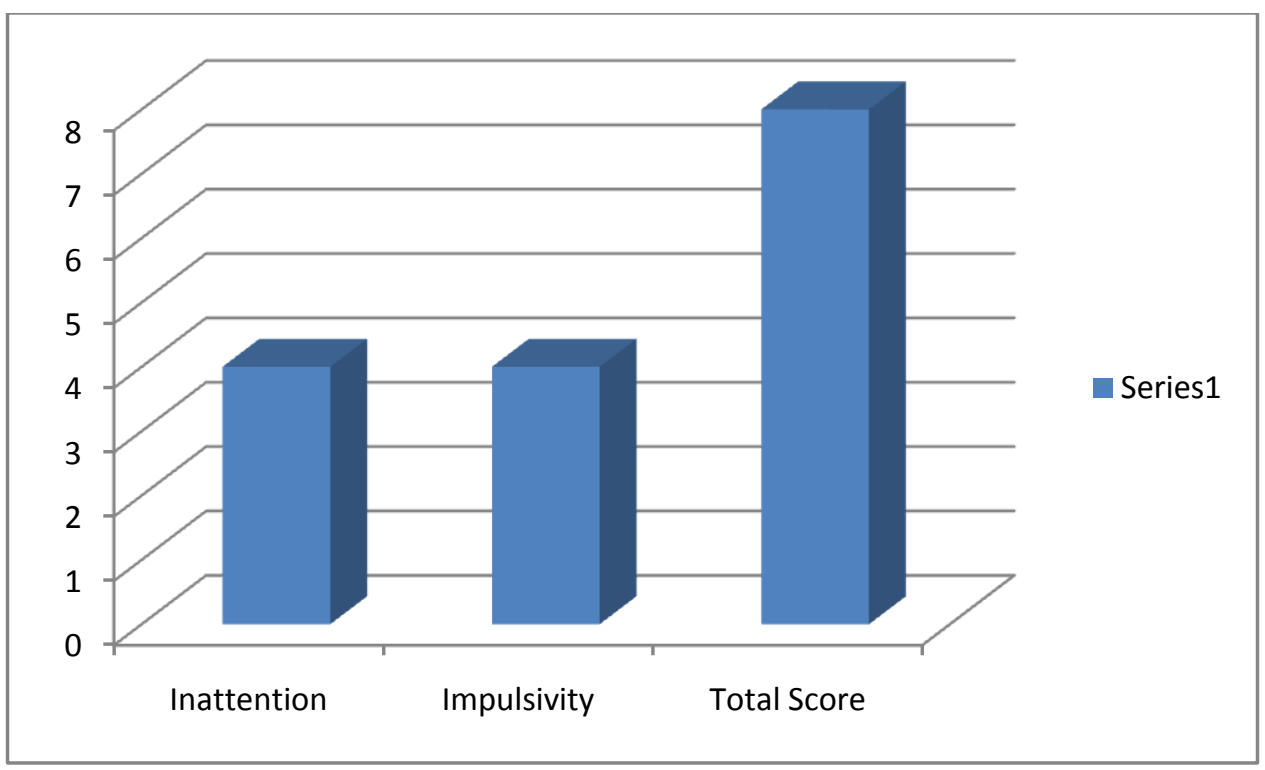

Table 2: Scores of Mast L Post Intervention

\begin{tabular}{|l|l|}
\hline Post Intervention Scores & 3 \\
\hline Inattention & 3 \\
\hline Impulsivity/Hyperactivity & 6 \\
\hline Total Score & \\
\hline
\end{tabular}




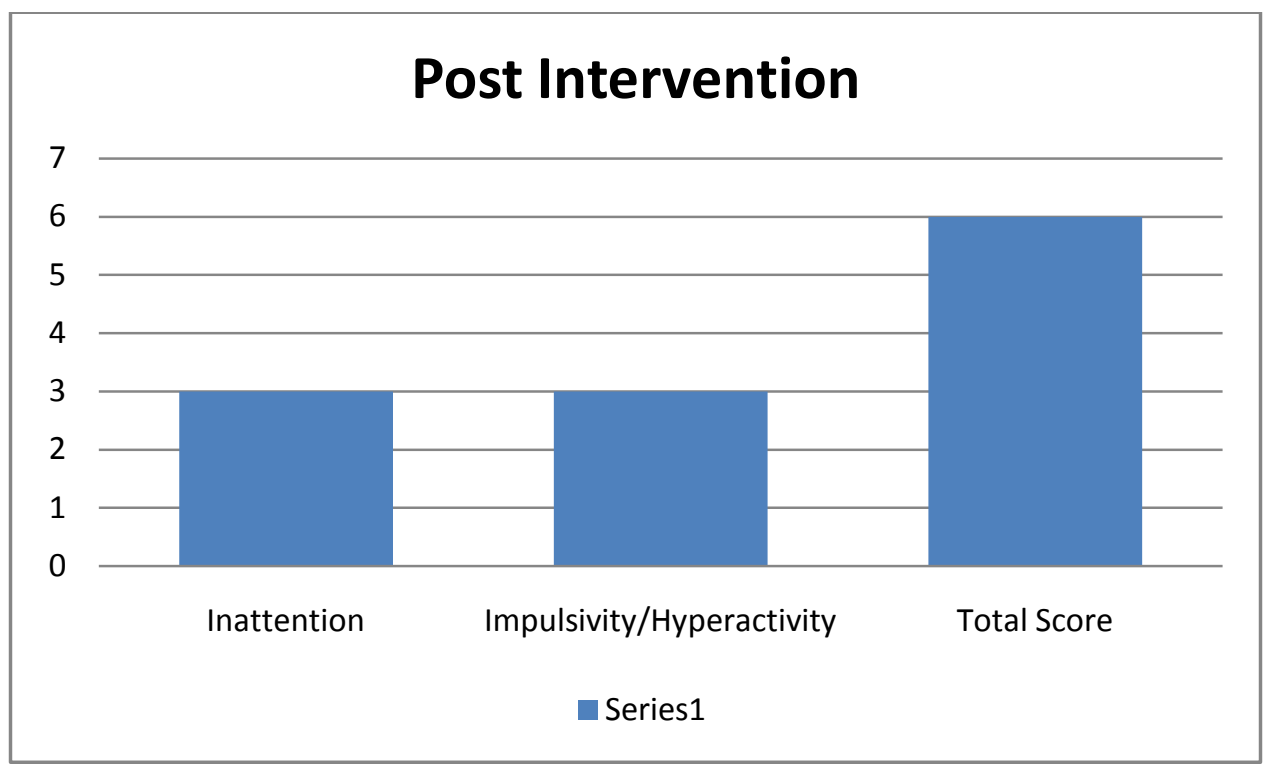

Table 1 depicts the scores of Master L's pre or baseline scores on Inattention and Hyperactivity, a score of 9 on inattention and 9 on hyperactivity and impulsivity, with total score of 18, Post intervention Table 2 depicts there was significant improvement in the three behavioral domains, the scores were 2 on inattention and 3 on hyperactivity and impulsivity, a total score of 8/18. There was significant difference in the domain of Inattention on items such as difficulty "organizing tasks and activities, which had a score of 1 post intervention it was 0 , a score of 3 each on items such as "avoids or strongly dislikes tasks that require sustained mental effort"(eg home work) and" Is easily distracted by external stimuli", post intervention the score reduced to 1 on each domain, a score of 2 on the item of "Is forgetful in daily activities" has reduced to 1 .

Scores pre intervention on domain Impulsivity and Hyperactivity, a score of 3 on items such as "Is on the go or acts driven by a move", "talks excessively and blurts out answer to questions before the questions have been completed", has reduced to score1 each post intervention

\section{Graph 3}

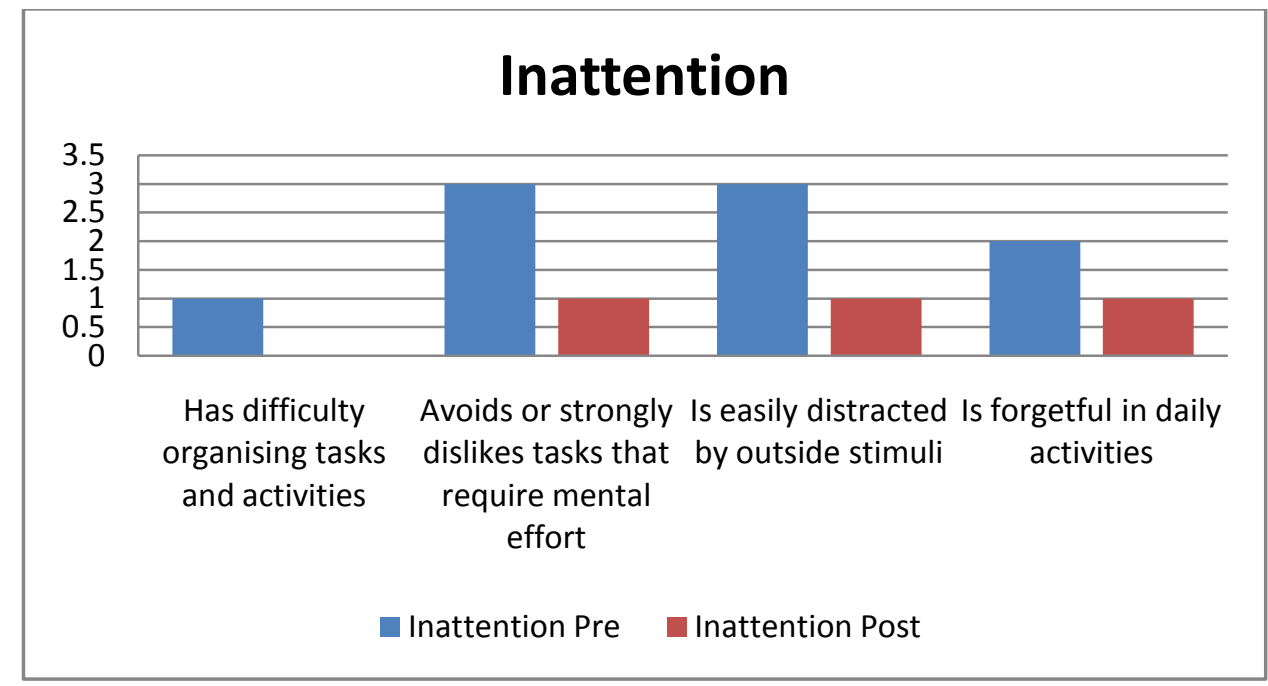




\section{Graph 4}

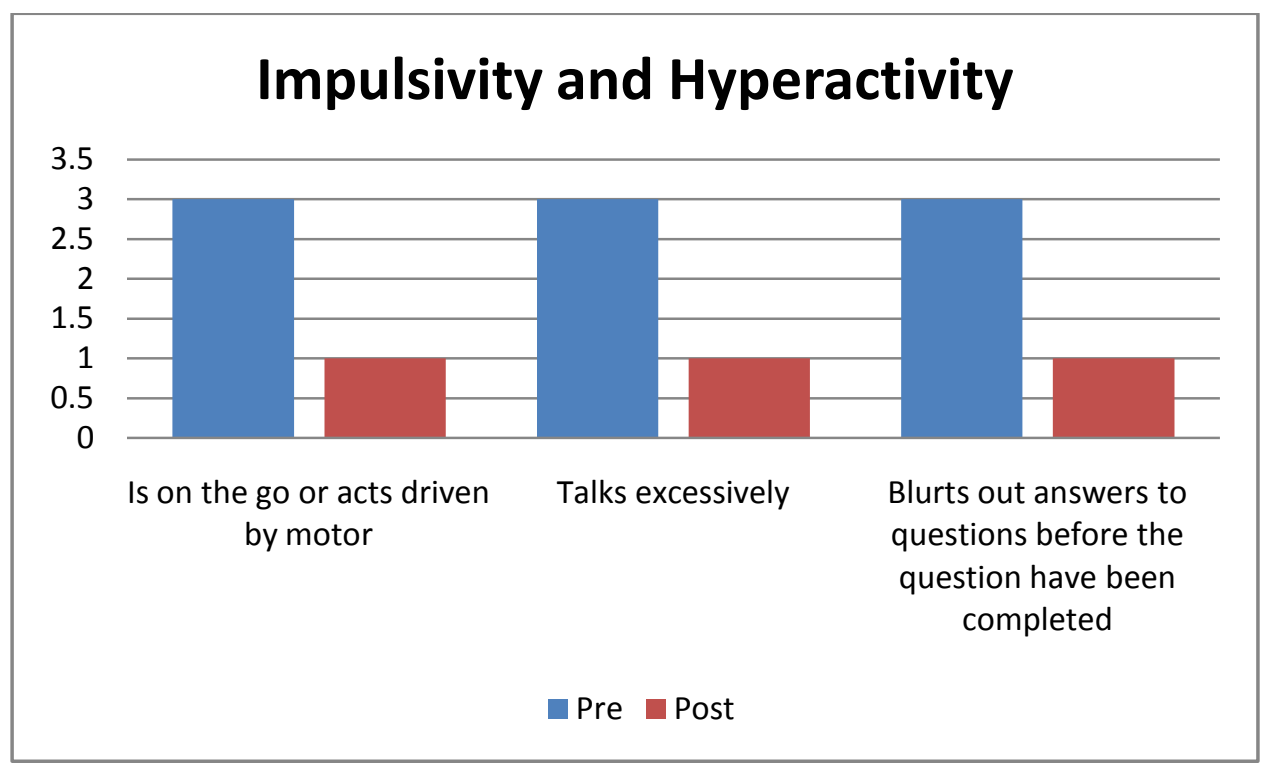

Graph 3 and Graph 4: Interpret domain wise graphical representation of Inattention and Hyperactivity and Impulsivity behaviors from Table 2.

\section{CONCLUSIONS}

Cognitive neuroscience has permitted a greater understanding of ADHD. Recent research and novel drug developments have provided new treatment options for adolescents and adults with ADHD. New stimulant formulations have made it possible to tailor treatment to the duration of efficacy required by patients and to help mitigate the potential for abuse, misuse and diversion. Although they tend to be less efficacious than stimulants, new non-stimulant options also allow for extended duration of treatment without the adverse consequences associated with stimulant therapy. Progress in non-medical therapies now provides several options for patients who cannot or will not use medications, and for the many medication-treated patients who continue to show residual disability.

Looking toward the future, research will need to address several unmet needs. Many treated people with ADHD continue to have problems with executive functioning and deficient emotional self-regulation. These problems persist in many patients even when the core ADHD symptoms (as outlined in the Diagnostic and Statistical Manual of Mental Disorders, Fourth edition (DSM-IV)) are effectively treated. Future treatment development should aim at developing both psychosocial and medical treatments for these areas of difficulty. Future treatment research should also work to define and achieve optimal treatment outcomes for people with ADHD. Although current treatments are effective for achieving substantial symptom reduction in most patients, more work is needed to achieve full symptom reduction, and to reduce the burden of ADHD-associated disabilities. 
There are also diagnostic challenges for clinicians that could be addressed by future research. ADHD symptoms, especially hyperactive-impulsive symptoms, tend to decline through adolescence into adulthood, so that the adult presentation of ADHD differs somewhat from the childhood presentation. Helping clinicians understand these differences, and how such differences should affect the application of diagnostic criteria requires more work.

Ideally, medical and psychological treatments should be tailored to the underlying pathophysiology of the patient. Theoretically, this should be possible by using the scientific literature on the neurobiology of ADHD with treatment outcome studies, as it is possible that patients with specific brain-imaging abnormalities or genetic variants would have different responses to treatments. To date, most of this work has been done in the area of pharmacogenetics which, although promising, cannot yet guide treatment choices.

In summary, although the science of ADHD and its application to diagnosis and treatment have made great strides, more work is needed to improve the lives of patients and families affected by the disorder.

\section{REFERENCES}

Abikoff, H. (1987). An evaluation of cognitive behaviour therapy for hyperactive children. In B.B. Lahey \& A.E. Kazdin (Eds.), Advances in clinical child psychology (pp. 171-216). New York: Plenum

Abikoff, H. (1991). Cognitive training in ADHD children: Less to it than meets the eye. Journal of Learning Disabilities, 24, 205-209.

Antshel et al. BMC Medicine 2011, 9:72 http://www.biomedcentral.com/1741-7015/9/72

Bandura, A. (1997). Self-efficacy: The exercise of control. New York: W.H. Freeman/Times Books/Henry Holt \& Co.

Barkley, R. A. (2006). Attention-deficit hyperactivity disorder: A handbook for diagnosis and treatment (3rd ed.). New York:

Beck, A. T. (2005). The current state of cognitive therapy: A 40-year retrospective. Archives of General Psychiatry, 62, 953-959.

Brestan, E. V., \& Eyberg, S. M. (1998) Effective psychosocial treatments of conduct-disordered children and adolescents: 29 years, 82 studies, and 5272 kids. Journal of Clinical Child Psychology, 27, 180-189

Butcher, J. N., Mineka, S., \& Hooley, J. M. (2010). Abnormal Psychology. Boston: Allyn \& Bacon.

Cameron, M. L., \& Robinson, V.M.J. (1980). Effects of cognitive training on academic and ontask behavior of hyperactive children. Journal of Abnormal Child Psychology, 8, 405419.

Candace S. Kohut \& Jac Andrews. The efficacy of parent training programs for ADHD children: A fifteen-year review. Developmental Disabilities Bulletin, 2004, Vol. 32, No. 2, pp. $155-172$

Chronis, A. M., Chacko, A., Fabiano, G. A., Wymbs, B. T., \& Pelham, W. E. (2004). Enhancements to the behavioral parent training paradigm for families of children with 
ADHD: Review and future directions. Clinical Child and Family Psychology Review, 7, $1-27$.

Diagnostic and Statistical Manual of Mental Disorders (DSM) IV TR

Green, H., McGinnity, A., Meltzer, H., Ford, T., \& Goodman, R. (2005). Mental Health of Children and Young People in Great Britain, 2004. A survey carried out by the Office for National Statistics on behalf of the Department of Health and the Scottish Executive. Basingstoke: Palgrave Macmillan.

Hechtman, L., Weiss, G., \& Perlman, T. (1984). Young adult outcome of hyperactive children who received long-term stimulant treatment. Journal of the American Academy of Child Psychiatry, 23, 261- 269.

Hinshaw, S. P. (1992). Externalizing behavior problems and academic underachievement in childhood and adolescence: Causal relationships and underlying mechanisms. Psychological Bulletin, 111, 127-155

Horn, W. F., Ialongo, N., Greenberg, G., Packard, T., \& Smith-Winberry, C. (1990). Additive effects of behavioral parent training and selfcontrol therapy with attention deficit hyperactivity disordered children. Journal of Clinical Child Psychology, 19(2), 98-110.

Jensen, P.S., Mrazek, D., Knapp, P. K., Steinberg, L., Pfeffer, C., Schowalter, J., \& Shapiro, T. (1997). Evolution and revolution in child psychiatry: ADHD as a disorder of adaptation. Journal of the American Academy of Child \& Adolescent Psychiatry, 36(12), 1672-1681.

Kendall, P. C., \& Braswell, L. (1993). Cognitive-behavioral therapy for impulsive children. New York: The Guilford Press

Kendall, P.C., \& Braswell, L. (1982). Cognitive-behavioral self-control therapy for children: A comprehensive analysis. Journal of Consulting and Clinical Psychology, 50, 672-689.

Muñoz-Solomando, A., Kendall, T., \& Whittington, C. J. (2008). Cognitive behavioural therapy for children and adolescents. Current Opinion in Psychiatry, 21(4), 332-7.

NICE (2009). Attention deficit hyperactivity disorder: Diagnosis and management of ADHD in children young people and adults. London, National Institute for Health and Clinical Excellence.

Pelham, W. E., Wheeler, T., \& Chronis, A. (1998). Empirically supported psychosocial treatments for attention deficit hyperactivity disorder. Journal of Clinical Child Psychology, 27, 190-205.

Tamm L, Trello-Rishel K, Riggs P, et al predictors of treatment response in adolescents with comorbid substance use disorder and attention-deficit/hyperactivity disorder. J Subst Abuse Treat. 2013 Feb;44(2):224-30. doi: 0.1016/j.jsat.2012.07.001. Epub 2012 Aug 11.

The Foundation for Medical Practice Education, www.fmpe.org The Guilford Press

Usher, E. L., \& Pajares, F. (2008). Sources of self-efficacy in school: Critical review of the literature and future directions. Review of Educational Research, 78(4), 751-796.

Winhusen TM, Lewis DF, Riggs PD, Davies RD, Adler LA, Sonne S, Somoza EC. J Child Adolesc Psychopharmacology. 2011 Oct ;21(5):455-63. doi:10.1089/cap.2011.0014.

How to cite this article: $\mathrm{R}$ Thyagarajan (2016), A Case Study Using Cognitive-Behavioral Therapy-Management of ADHD, International Journal of Indian Psychology, Volume 3, Issue 3, No. 8, DIP: 18.01.140/20160303, ISBN: 978-1-365-12176-0 